\title{
Lead isotope trends and sources in the atmosphere at the artificial wetland
}

\author{
Ling Cong ${ }^{1}$, Jiexiu Zhai ${ }^{1}$, Guoxin Yan ${ }^{1}$, Jiakai Liu ${ }^{1}$, Yanan Wu ${ }^{1}$, Yu Wang ${ }^{1}$, Zhenming Zhang ${ }^{\text {Corresp., } 1}{ }^{1}$, Mingxiang \\ Zhang ${ }^{\text {Corresp. } 1}$ \\ ${ }^{1}$ College of Nature Conservation, Beijing Forestry University, Beijing, China \\ Corresponding Authors: Zhenming Zhang, Mingxiang Zhang \\ Email address: zhenmingzhang@bjfu.edu.cn, mingxiangzhang2019@163.com
}

With the rapid development of industry, studies on lead pollution in total suspended particulate matter (TSP) have received extensive attention. This paper analyzed the concentration and pollution sources of lead in the Cuihu Wetland in Beijing during the period of 2016-2017. The results show that the lead contents in TSP in the Cuihu Wetland were approximately equal in summer and spring, greater in winter, and greatest in autumn. The corresponding lead concentrations were $0.052 \mathrm{ng} / \mathrm{m}^{3}, 0.053 \mathrm{ng} / \mathrm{m}^{3}, 0.101$ $\mathrm{ng} / \mathrm{m}^{3}$, and $0.115 \mathrm{ng} / \mathrm{m}^{3}$, respectively. We compared the ${ }^{206} \mathrm{~Pb} /{ }^{207} \mathrm{~Pb}$ data with other materials to further understand the potential sources of atmospheric lead. The mean values of ${ }^{206} \mathrm{~Pb} /{ }^{207} \mathrm{~Pb}$ from spring to winter were 1.082, 1.098, 1.092, and 1.078, respectively. We found that the lead sources may be associated with coal burning, brake and tire wear, and vehicle exhaust emissions. We also calculated the enrichment factor values for the four seasons, and the values were all much greater than 10 , indicating that the lead pollution is closely related to human activities. 
1 Lead isotope trends and sources in the atmosphere at the artificial wetland

2 Ling Cong, Jiexiu Zhai, Guoxin Yan, Jiakai Liu, Yanan Wu, Yu Wang, Zhenming Zhang*,

3 Mingxiang Zhang*

4

5 College of Nature Conservation, Beijing Forestry University, Beijing, China

6

7 Corresponding Authors:

8 Zhenming Zhang*, Mingxiang Zhang*

9 *Email address: Zhenmingzhang@bjfu.edu.cn, mingxiangzhang2019@163.com

10 


\section{Abstract}

12 With the rapid development of industry, studies on lead pollution in total suspended particulate

13 matter (TSP) have received extensive attention. This paper analyzed the concentration and

14 pollution sources of lead in the Cuihu Wetland in Beijing during the period of 2016-2017. The

15 results show that the lead contents in TSP in the Cuihu Wetland were approximately equal in

16 summer and spring, greater in winter, and greatest in autumn. The corresponding lead

17 concentrations were $0.052 \mathrm{ng} / \mathrm{m}^{3}, 0.053 \mathrm{ng} / \mathrm{m}^{3}, 0.101 \mathrm{ng} / \mathrm{m}^{3}$, and $0.115 \mathrm{ng} / \mathrm{m}^{3}$, respectively. We

18 compared the ${ }^{206} \mathrm{~Pb} /{ }^{207} \mathrm{~Pb}$ data with other materials to further understand the potential sources of

19 atmospheric lead. The mean values of ${ }^{206} \mathrm{~Pb} /{ }^{207} \mathrm{~Pb}$ from spring to winter were $1.082,1.098,1.092$,

20 and 1.078, respectively. We found that the lead sources may be associated with coal burning,

21 brake and tire wear, and vehicle exhaust emissions. We also calculated the enrichment factor

22 values for the four seasons, and the values were all much greater than 10 , indicating that the lead

23 pollution is closely related to human activities.

24 Keywords: Total suspended particulate matter - Lead concentration · Lead isotope ratio ·

25 EF values $\cdot$ Artificial wetland

\section{Introduction}

27 Air pollution especially particulate matters' pollution has become an issue in the public eye in 28 China (Florig 1997). Particulate matter pollution not only adversely affects human health, but 29 also acts as a catalyst for climate change (Seaton et al. 1995; Kyotani,Iwatsuki 2002). Studies

30 have shown a positive correlation between air pollution and respiratory system diseases like lung

31 cancer (Dockery et al. 1993). Researchers found that atmospheric aerosols can affect cloud 32 microphysics and indirectly cause changes in light radiation to affect climate (Charlson,Hofmann 33 1992; Dickerson et al. 1997). Aerosol particles are a mixture of liquid and solid materials which 
34 contains trace metals, ions, and organic compounds and so on (Gang 2015). Total suspended

35 particulate matters (TSP) played an important role in analyzing aerosols' chemical constitution,

36 studying the spatial and temporal variations, revealing the relationship with meteorological

37 factors, and tracing sources (Cong et al. 2018; Ragosta et al. 2002). Atmospheric input of heavy

38 metal elements has a long-term adverse impact on the geobiochemical cycle of ecosystems

39 (Kelly et al. 1996). Therefore, it is imperative to understand the heavy metals in TSP.

40 Trace metals such as $\mathrm{Pb}, \mathrm{Cd}, \mathrm{Hg}$, and $\mathrm{Cr}$ are biologically non-functional and are highly toxic

41 (Salt et al. 1995). Lead has been designated as one of the most dangerous environmental

42 pollutants by the United Nations Environment Programme (Morel 2008; Shi et al. 2008). With

43 the rapid development of industry, anthropogenic $\mathrm{Pb}$ has become the major source of the lead in

44 the environment. They were widespread in the atmosphere, soil, water, plants and animals

45 (Wang et al. 2013). It is very important to study the geochemical cycle of lead in the

46 environment (Hao et al. 2008; Dawson et al. 2010; Bove et al. 2011; Uzu et al. 2010).

47 Lead has four stable isotopes which can be used as a tracer of anthropogenic pollution. ${ }^{206} \mathrm{~Pb}$,

$48{ }^{207} \mathrm{~Pb}$ and ${ }^{208} \mathrm{~Pb}$ are three radiogenic isotopes while ${ }^{204} \mathrm{~Pb}$ is non-radiogenic isotope. These four

49 isotopes can be used as a "footprint" for different sources of lead pollution in the environment,

50 especially for the human activities (Grousset et al. 1994). The inductively coupled plasma-mass

51 spectrometry (ICP-MS) was designed for analyzing stable isotopes more precisely, especially for

$52 \mathrm{~Pb}$. The development of ICP-MS made it possible to trace the sources and investigation of heavy

53 metals in different materials. It is widely used to identify the natural sources and anthropogenic

54 pollution (Wiederhold 2015). The unique lead isotope ratio ranges make it easier to find out the

55 major sources of lead, even though sometimes it may be overlapped (Wang et al. 2013; Bindler

56 et al. 1999; Bollhöfer, Rosman 2001; Veysseyre et al. 2001; Kaste et al. 2003; Zhang et al. 2007). 
57 This makes scientists more convenient to identify and quantify the sources of lead in different

58 environmental samples (e.g., atmospheric deposition (Gallon et al. 2005), sediment (Dang et al.

59 2015), and soil (Huang et al. 2015)), as well as in organisms (Martinez-Haro et al. 2011).

60 Cuihu wetland is the only national urban wetland park in Beijing, which has an area of $1.57 \mathrm{~km} 2$.

61 It is one of the most typical artificial wetland, which is constructed to improve the environmental

62 conditions. Also it plays important roles in hydrological and economic aspects, especially in

63 keeping biological diversity. However, Cuihu wetland is open only in certain days and strictly

64 controls the number of tourists and their activities, which is not like other wetlands in Beijing,.

65 Thus, Cuihu wetland is less affected by different human activities. This makes Cuihu wetland a

66 good place for scientific research. It is reported that artificial wetland is a long term green

67 technology to remove the heavy metals from the polluted areas (Huang et al. 2017), such as Pb.

68 It can also theoretically influence the heavy metal air pollution by increasing humidity and

69 decreasing temperature. The transport of particulates is associated with a series of

70 biogeochemical processes of chemical compounds such as heavy metals (Henderson 2002). Thus

71 the variation of heavy metals is also connected with the changes of meteorological factors such

72 as humidity and temperature. This in contrary can also provide important information about

73 particle cycling processes (Sun et al. 2016).

74 However, there were few studies focused on atmospheric lead pollution in an artificial wetland in

75 Beijing. On the other hand, it is difficult to make a systematic research about the lead pollution

76 in the particles by only knowing their total concentrations. Thus, efforts must be made to identify

77 the possible lead sources of the total suspended particulate matters, thus, to control and reduce

78 the air pollution (Zheng et al. 2004). Therefore, we studied atmospheric lead concentrations and

79 lead isotopic ratios in the Cuihu Wetland in Beijing. We analyzed the temporal variations of lead

80 in TSP in the Cuihu Wetland and compared the differences of lead pollution in atmosphere over

81 different regions and land use types. Another primary target of this study is to determine the

82 sources of lead. We measured lead isotopic ratios in TSP and calculated the enrichment factor

83 (EF) values over a year. Based upon the results, the study attempts to examine the effects of 
84 human activity on $\mathrm{Pb}$ in the atmosphere and the potential sources of $\mathrm{Pb}$ in the total suspended

85 particulate matter in the region. It is helpful for us to have a systematic acknowledgement on the

86 lead pollution in the TSP of the air in an artificial wetland.

\section{Materials and methods}

\subsection{Sampling site}

89 The Cuihu wetland is a typical country wetland located north of the Shangzhuang Reservoir in the Haidian District of Beijing. The area of the Cuihu Wetland is $1.57 \mathrm{~km}^{2}$, of which approximately $0.09 \mathrm{~km}^{2}$ is water with an approximate maximum length and width of $1.9 \mathrm{~km}$ and $1.2 \mathrm{~km}$, respectively.

93 The weather is rainy and hot in summer (June-September) and dry and cold in winter

94 (December-March). Spring (March-June) and autumn (September-December) are short.

95 The sampling site was on Crane Island near the center of the Cuihu Wetland (Fig. 1). The

96 island's main vegetation is willow (Salix babylonica), with reeds (Phragmites communis)

97 growing on the more flat areas of the island.

\subsection{Sampling process}

An intelligent medium-flow total suspended particle sampler (TH-150, Wuhan Tianhong Instruments Co., Ltd) and Teflon filters (Beijing RyderCase Instruments Co., Ltd) were used to

101 collect TSP. A microwave digestion system is used in the key step of the pretreatment. Samples

102 of atmospheric particulates were digested by microwave digestion system, and $\mathrm{Al}$ and $\mathrm{Pb}$ were

103 determined by ICP-MS. The advantages of microwave digestion system are: quick heating,

104 strong resolution ability and short dissolution time. Besides, the digestion process is in an airtight

105 container. It can save acid reagent and reduce the interference of impurity elements. Its 
106 disadvantage is that it needs manual acid driving and it may induce a lower average data. The

107 sampling flow rate was fixed at $100 \mathrm{~L} \mathrm{~min}^{-1}$. The filters were put in an open plastic bag and

108 conditioned in a constant temperature $\left(25^{\circ} \mathrm{C}\right)$ and humidity $(50 \%)$ chamber for $24 \mathrm{~h}$ before and

109 after sampling (Marcazzan et al. 2001). The filters were transported to and from the sampling

110 site in sealed plastic boxes.

111 Ambient TSP samples were collected at the sampling site on Crane Island from September 2016

112 to August 2017. Three samples were collected simultaneously at the site during each of the four

113 seasons during the year. The duration per sample was $12 \mathrm{~h}$ (from 08:00 to 20:00).

\section{$114 \quad 2.3$ Chemical analysis}

115 The determinations of lead concentration, aluminum concentration and the lead isotopic

116 composition $\left({ }^{206} \mathrm{~Pb},{ }^{207} \mathrm{~Pb}\right.$, and $\left.{ }^{208} \mathrm{~Pb}\right)$ were performed via inductively coupled plasma-mass

117 spectrometry (Bi et al. 2007; Dai, 2015). A quarter of a filter sample was first placed in a Teflon

118 digestion vessel. Then, $8 \mathrm{~mL}$ of nitric acid $(6 \%, \mathrm{v} / \mathrm{v})$ and $2 \mathrm{~mL}$ of hydrogen peroxide were added

119 to the vessel. The vessel was covered and placed in a microwave digestive system to dissolve the

120 sample. The sample digestion was performed then. The first procedure is to heat the samples to

$121150^{\circ} \mathrm{C}$ in 10 minutes and remaining for 10 minutes. The second procedure is to heat them to $210^{\circ} \mathrm{C}$

122 in 5 minutes and remaining for 20 minutes. Then, the sample solution and filter residue mixture

123 were transferred to a Teflon crucible to heat at $150^{\circ} \mathrm{C}$ until nearly dry; $5 \mathrm{~mL}$ of nitric acid $(6 \%$,

$124 \mathrm{v} / \mathrm{v}$ ) was then added to the vessel for $15 \mathrm{~min}$ to dissolve the filter residue. After cooling, the

125 solution was diluted with nitric acid $(1 \%, \mathrm{v} / \mathrm{v})$ and then used to determine the metal elements.

126 Finally, the solution was measured using an ICP-MS to determine the lead and aluminum

127 concentration and the lead isotopic composition. An international reference material (SRM 981

128 common $\mathrm{Pb}$ isotopic standard) was used for calibration and analytical control before the samples 
129 were measured. The precision $(\% \mathrm{RDS})$ of the $\mathrm{Pb}$ isotopic ratios was typically $<0.5 \%$.

\section{$130 \quad 2.4$ Statistical analysis}

131 The statistical treatments of the data were performed using SigmaPlot 12.5 and the IBM SPSS

132 Statistics 22 statistical software.

\section{$133 \quad 2.5$ Enrichment factor analysis}

134 We calculated the enrichment factors (EF) to identify the origin of lead and to calculate the

135 proportions of the anthropogenic sources (Mai, Lee 2010; Yang et al. 2010). In previous studies,

136 these measures have been effective tools to distinguish different sources of heavy metals such as

137 natural sources and anthropogenic sources (Petaloti et al. 2006; Ayrault et al. 2010). The value of

138 EF is caculated via the following relationship:

$$
\mathrm{EF}=\left(\frac{[\mathrm{E}]}{[\mathrm{R}]}\right) \text { sample } /\left(\frac{[\mathrm{E}]}{[\mathrm{R}]}\right) \text { crust, }
$$

where $\mathrm{E}$ is the considered element, $\mathrm{R}$ represents the reference element for crustal material,

$141([\mathrm{E}] /[\mathrm{R}])$ sample is the concentration ratio of $\mathrm{E}$ to $\mathrm{R}$ in the aerosol sample, and $([\mathrm{E}] /[\mathrm{R}])$ crust

142 indicates the mean concentration ratio of $\mathrm{E}$ to $\mathrm{R}$ in the crust (Han et al. 2006).

$143 \mathrm{Al}$ is abundant in the earth's crust and is frequently used as a reference element (Han et al. 2006;

144 Taylor,Mclennan 1995; Duan et al. 2012). We calculated the EFs using the value of Al in

145 Chinese soil in 1990, due to the stability and lack of anthropogenic sources. Many of the studies

146 were focused on the concentration changes of different heavy metals. They usually measured the

147 concentrations in surface soils. We found that in 1990, it has been measured of the $\mathrm{Al}$ and $\mathrm{Pb}$

148 concentrations of parent rock that $\mathrm{Al}$ was $6.62 \%$, and $\mathrm{Pb}$ was $26 \mathrm{mg} / \mathrm{kg}$ (Wei et al. 1991). If EF

149 approaches unity, the parent rock is the predominant source of the element. Operationally, given 
150 the local variation in the soil composition, if EF $>10$, it can be assumed that the anthropogenic

151 pollution is the primary source of the elemental abundance (Basha et al. 2010).

\section{Results}

\section{3.1 Concentration of lead in atmosphere particles}

154 Figures 2 and 3 show TSP and Pb concentrations $( \pm \mathrm{SE})$ in the samples, respectively.

155 The concentrations of TSP were more than 1000 times greater than the $\mathrm{Pb}$ concentrations. The

156 summer season has the lowest concentrations of TSP at $68.867 \mathrm{ng} / \mathrm{m}^{3}$. The highest

157 concentrations are seen in winter at $244.213 \mathrm{ng} / \mathrm{m}^{3}$. The TSP concentration in spring is higher

158 than that in autumn, with values of $171.528 \mathrm{ng} / \mathrm{m}^{3}$ and $101.042 \mathrm{ng} / \mathrm{m}^{3}$, respectively. However,

159 the seasonal trend is slightly different for TSP and lead. The average concentrations of lead in

160 the four seasons vary from $0.052 \mathrm{ng} / \mathrm{m}^{3}$ to $0.115 \mathrm{ng} / \mathrm{m}^{3}$. The lowest concentration of lead was

161 recorded during summer and spring followed by winter, while the highest concentration was

162 found during autumn at $0.115 \mathrm{ng} / \mathrm{m}^{3}$. The concentrations in spring and summer were $0.052 \mathrm{ng} / \mathrm{m}^{3}$

163 and $0.053 \mathrm{ng} / \mathrm{m}^{3}$, respectively. The concentration was approximately $0.101 \mathrm{ng} / \mathrm{m}^{3}$ in winter.

164 Even though the concentrations in autumn and winter are higher than those in spring and summer,

165 the only significant difference is between autumn and summer $(P<0.05)$. There were no

166 significant differences between the other seasons.

\section{$167 \quad 3.2$ Sources of atmospheric lead}

168 The lead isotope compositions in the four seasons are shown in Table 1. In general, the samples

169 show a wide range of lead isotope ratios, ranging from 36.145 to 37.949 for ${ }^{208} \mathrm{~Pb} /{ }^{204} \mathrm{~Pb}$, from

1702.094 to 2.206 for ${ }^{208} \mathrm{~Pb} / 206 \mathrm{~Pb}$, from 15.129 to 15.773 for ${ }^{207} \mathrm{~Pb} /{ }^{204} \mathrm{~Pb}$, from 16.490 to 18.121 for

$171{ }^{206} \mathrm{~Pb} /{ }^{204} \mathrm{~Pb}$, and from 1.061 to 1.168 for ${ }^{206} \mathrm{~Pb} /{ }^{207} \mathrm{~Pb}$ (Table 1 ). ${ }^{206} \mathrm{~Pb} /{ }^{207} \mathrm{~Pb}$ is relatively important 
172 in studying the sources of lead in the environment, as it can be determined precisely. The

$173{ }^{206} \mathrm{~Pb} /{ }^{207} \mathrm{~Pb}$ isotope ratio revealed differences in the behavior in different seasons at the sampling 174 site.

\section{$175 \quad 3.3$ Enrichment factors}

176 Figure 4 shows the EFs of lead for TSP in the four seasons using Al as the reference element.

177 The EFs represent the enrichment or depletion of lead in the samples.

178 If an element's EF value is less than 10, it can be considered to be a crustal (or topsoil) source 179 that is primary caused by soil- or rock-weathered dust blowing into the atmosphere. If the EF

180 value is much greater than 10, e.g., tens to tens of thousands, the element is likely enriched and

181 reflects not just the contribution of crustal material but may also be related to contributions from 182 different human activities.

183 The EF values in TSP for each season varied substantially from 214 (summer) to 9623 (autumn).

184 The average EF value of lead is 805 in spring, 557 in summer, 5133 in autumn, and 3008 in 185 winter.

\section{Discussion}

\section{4.1 Variations of lead concentrations in TSP}

188 The Cuihu Wetland is a typical country wetland in Beijing and is little affected by outside

189 conditions in comparison with some industrial sites, which are influenced by heavy metals and

190 related to manufacturing processes. The average lead concentrations in Cuihu Wetland were

191 enough low which were even below the safe limits of the international agencies. The WHO and

192 USEPA standard for atmospheric lead is $0.500 \mathrm{ng} / \mathrm{m}^{3}$ (Health 2000). During the present study,

193 the average concentration of lead $\left(0.080 \mathrm{ng} / \mathrm{m}^{3}\right)$ was found to be below the limits of the WHO 
194 and USEPA standard. The reason for the lower concentration of lead in the atmospheric

195 particulate matter in Cuihu may be self-purification of the wetlands and its distance from large

196 industrial areas. Even though there is a main road which is a practice road for driving school

197 students and a road to transport sand from one sand mining plant. This makes the lead

198 concentrations lower than in areas with many factories or other sources of lead pollution. In

199 addition, the difference between the lead concentrations in the local atmosphere and the WHO

200 level may be due to the different situations of the climate especially the metrological data during

201 the research. We can refine the experimental data by performing additional repetitions and

202 increasing the number of samples.

203 Variations in average lead levels showed the following sort during the study period: levels in

204 summer were approximately equal to levels in spring, levels in winter were greater, and levels in

205 autumn were the greatest, which is slightly different from a study in Islamabad during the period

206 of 2004-2005, were the levels in summer were approximately equal to the levels in spring, levels

207 in autumn were greater, and levels in winter were greatest (Shah \& Shaheen et al. 2008). The

208 results show that the metal content is inversely proportional to temperature. Even though the

209 concentration of lead in autumn is higher than that in winter, the difference between them is not

210 significant (Kim et al. 1997; Kim et al. 2002; Mishra et al. 2004). Studies have found positive

211 relationships of lead with relative humidity and negative relationships of lead with the

212 temperature (Jonsson et al. 2004; Kim et al. 1997). Other studies show that the wind speed

213 appreciably affects the spread of trace metals. For example, it is shown that the wind speed

214 affects the dilution of lead in the environment (Ki et al. 2002; Vallius et al. 2005; Fang et al.

215 2002; Ragosta et al. 2002). Furthermore, studies show that the rainfall scavenging is of great

216 efficiency in removing heavy metals from the atmosphere (Mircea et al. 2000). 
217 Data for lead concentrations in the Cuihu Wetland and other sites are listed in Table 2. We

218 selected nine different types of sampling sites. The lead concentration in the Cuihu Wetland is

219 approximately 4-8 times higher than those in wetlands in Taiwan, with values of $0.010 \mathrm{ng} / \mathrm{m}^{3}$

220 and $0.025 \mathrm{ng} / \mathrm{m}^{3}$, respectively (Guor et al. 2010; Fang \& Chang 2012). The annual concentration

221 of lead in the Cuihu Wetland is similar to that in Haeng Goo Dong, Korea, which was sampled in

222 a grassland (Kim 2004). Another study of lead in TSP in Beijing had a concentration of 0.690

$223 \mathrm{ng} / \mathrm{m}^{3}$, which exceeds the limit of the WHO and USEPA standard. Okuda et al. (2008) conclude

224 that coal combustion as a major source of some anthropogenic metals. During 1995-2004 there is

225 a large amount of coal for heating supply and residential use in Beijing. Even though that the

226 location for coal combustion for urban residential heating has changed from the domestic stove

227 to large heating supply facilities in recent years. It is also estimated that there is an annual

228 increase in $\mathrm{Pb}$ concentration. On the other hand, nonferrous metal smelters are also possible

229 sources. However, efforts must be made to lower the lead concentration. The lead concentrations

230 in forests were very low, followed by grasslands (Wang et al. 2016; Kim 2004; Quiterio et al.

231 2006). Lead concentrations appeared higher in industrial areas (Ki et al. 2002; Shaheen et al.

232 2005; Shah, Shaheen 2007). However, this also depends on the meteorological parameters when

233 the samples were collected and levels are very different in different cities.

\section{$234 \quad 44.2$ Sources of lead from nature and human activities}

235 Regardless of the lead sources (lithogenic or anthropogenic), the average ${ }^{206} \mathrm{~Pb} / 207 \mathrm{~Pb}$ ratio in the

236 four seasons followed the order: summer $(1.098)>$ autumn $(1.092)>\operatorname{spring}(1.082)>$ winter

237 (1.078). It is indicated that the geochemical background $\mathrm{Pb}$ has relatively high ${ }^{206} \mathrm{~Pb} /{ }^{207} \mathrm{~Pb}$

238 (approximately 1.200), while low ${ }^{206} \mathrm{~Pb} /{ }^{207} \mathrm{~Pb}$ ratios may indicate potential anthropogenic inputs

239 (Lee et al. 2007). Thus, it could be inferred that in winter one source with low ${ }^{206} \mathrm{~Pb} /{ }^{207} \mathrm{~Pb}$ ratio 
240 dominates over others.

241 The lead isotope compositions of the TSP are helpful to further understand the potential sources

242 of atmospheric lead. We compared the ${ }^{206} \mathrm{~Pb} /{ }^{207} \mathrm{~Pb}$ and ${ }^{208} \mathrm{~Pb} /{ }^{206} \mathrm{~Pb}$ data with that of other

243 materials (Table 3). Due to the Th-rich environment in China, relatively high ${ }^{208} \mathrm{~Pb}$ abundances

244 may interfere with estimations of contributions from alkyl lead additives (Chen et al. 2005).

245 Therefore, in the following discussion, we give priority to the influence of ${ }^{206} \mathrm{~Pb} / 207 \mathrm{~Pb}$. The

246 results show that the average ratios of TSP in spring are in the range of 1.063-1.098, which is

247 closest to leaded vehicle exhaust (Mukai et al. 1993). In addition, the ${ }^{206} \mathrm{~Pb} / 207 \mathrm{~Pb}$ isotope ratios in

248 autumn are $1.061-1.132$, which are similar to those in spring. The ${ }^{208} \mathrm{~Pb} / 206 \mathrm{~Pb}$ analysis results are

249 consistent with those of ${ }^{206} \mathrm{~Pb} / 207 \mathrm{~Pb}$. Chen et al. (2015) conclude that the ${ }^{206} \mathrm{~Pb} /{ }^{207} \mathrm{~Pb}$ ratios from

250 leaded gasoline range from 1.097 to 1.116. Moreover, Han et al. (2016) indicate that the average

$251{ }^{206} \mathrm{~Pb} /{ }^{207} \mathrm{~Pb}$ isotope ratio of unleaded vehicle exhaust is 1.147 . It seems plausible to assume that

252 the $\mathrm{Pb}$ pollution may derive from both the leaded and unleaded gasoline via atmospheric

253 deposition. The Cuihu Wetland is very close to a road, which is a training route for a driving

254 school that has more students in spring and autumn. This indicates that traffic plays an important

255 role in lead emissions. However, unleaded gasoline has been widely promoted in China, which

256 makes high concentrations of lead controversial. Before unleaded gasoline was introduced, lead

257 has been widely released into the environment via leaded gasoline used in vehicles over several

258 decades. Those $\mathrm{Pb}$ is of high possibility to be settled into the soil. Such concentrations may be

259 due to the high lead emissions that entered the atmosphere over the past decades, resulting in a

260 relatively high concentration of lead in the soil along the roadside. The movement of vehicles

261 can act to re-suspend dust containing lead into the air (Shah et al. 2006; Ragosta et al. 2002; Kim

262 et al. 2002; Shah \& Shaheen 2008). It is thought that the sand mining plant near the Cuihu 
263 Wetland also plays an important role in increasing the lead concentration. Lead isotope ratios of

264 Chinese coal are reported to vary widely (Mukai et al. 2001). It is interesting that the lead

265 contents in coal are enough low, while they are high in the coal combustion dust samples. This

266 may be due to the fact that combustion process has a "concentration effect" on the emission of

267 lead into the atmosphere (Chen et al. 2005). The ${ }^{206} \mathrm{~Pb} /{ }^{207} \mathrm{~Pb}$ isotope ratios in summer ranged

268 from 1.069 to 1.168 , which reflects several factors, such as leaded vehicle exhaust, unleaded

269 vehicle exhaust, and coal. The ${ }^{208} \mathrm{~Pb} /{ }^{206} \mathrm{~Pb}$ ratios indicate that the major source of lead is coal. In

270 winter, the isotope ratios of and ${ }^{208} \mathrm{~Pb} /{ }^{206} \mathrm{~Pb}$ were $1.069-1.200$ and $2.160-2.202$, respectively.

271 Han et al. (2016) has reported that $\mathrm{Pb}$ from coal appeared to be larger than 1.17. It is one of the

272 indicators that one of the sources of lead is coal (Han et al. 2016). Besides, coal is used as winter

273 heating in Cuihu wetland. The ${ }^{206} \mathrm{~Pb} /{ }^{207} \mathrm{~Pb}$ values indicate the contribution of three sources: coal,

274 metallurgic dust, and industrial sources. Meanwhile, the ${ }^{208} \mathrm{~Pb} /{ }^{206} \mathrm{~Pb}$ values are very close to

275 those of coal. Increased coal burning in winter is therefore the main source of lead. Trace

276 elements were released into the atmosphere throughout coal combustion via bottom ash, fly ash

277 and gaseous phase. The release of heavy metals depends on the composition of the coal and also

278 on gas temperature and residence time in the flue gas (Mariepierre Pavageau et al. 2002). Studies

279 have also shown that more than $50 \%$ of lead in coal may be released into the atmosphere during

280 normal coal pyrolysis processes (Zajusz-Zubek \& Konieczyński 2003). This reminds us that it is

281 of great significance to control the combustion and emission process in ways of reducing the lead

282 pollution in the air.

\section{$283 \quad 4.3$ Enrichment factors of lead}

284 It is obvious that lead in the atmospheric particles came from anthropogenic sources. The highest

285 EF value is found in autumn samples, which also had the highest lead concentration. It can be 
seen that the EF variation is similar to the trend in the $\mathrm{Pb}$ concentrations, which is autumn $>$

287 winter $>$ spring $>$ summer. These findings indicate that the variation in lead is closely related to

288 human activities. The lead sources are associated with coal burning, brake and tire wear, vehicle

289 exhaust emissions, and the metal industry (Hieu, Lee 2010; Xu et al. 2013). One possible reason

290 for the high EF values is that the Cuihu Wetland is fairly close to a main road, which is a training

291 route for a driving school. This may increase the opportunity for pollution via brake and tire

292 wear and vehicle exhaust emissions. However, coal burning in autumn and winter also leads to

293 an increase in lead from anthropogenic sources. Other studies have also shown a similar lead

294 enrichment in other places of China (Pan et al. 2015). One study surveyed the EFs in TSP

295 measured at five sites from 2009 to 2010. The results showed that lead was highly enriched in

296 TSP samples in Beijing, Tianjin, Baoding, Tangshan, and Xinglong, with EFs exceeding 100.

297 These high EFs indicate that the lead is of anthropogenic origin, is a key tracer of coal burning

298 (Degen 1963), and is rich in particles emitted from fossil fuels and biofuel burning (Christian et

299 al. 2009; Wang et al. 2008).

300 Enrichment factors have been widely used to evaluate the anthropogenic/natural contributions of

301 trace elements (Duce et al. 1975; Polidori et al. 2009). However, the size distribution of the

302 particulate matters or soil samples was another important factor that affects the enrichment of

303 lead (Farao et al. 2014; Li et al. 2013). Therefore, more efforts must be done to figure out the

304 effect of the size distribution to the sources of lead.

\section{Conclusions}


306 This study showed that the lead concentrations in TSP vary from $0.055 \mathrm{ng} / \mathrm{m}^{3}$ to $0.115 \mathrm{ng} / \mathrm{m}^{3}$

307 during a year. The average lead concentrations exhibited the following pattern during the study

308 period: the level in summer was approximately equal to that in spring, levels in winter were

309 greater, and levels in autumn were greatest. The lead isotope ratio proved to be a useful tool to

310 characterize the source of the atmospheric lead contamination. Regardless of the lead source, the

311 average ${ }^{206} \mathrm{~Pb} / 207 \mathrm{~Pb}$ ratio in the four seasons followed the order: summer $(1.098)>$ autumn $(1.092)>$

312 spring (1.082) > winter (1.078). We also calculated the EF values in TSP for each season. These

313 findings indicate that the variation in lead is closely related to human activities. The sources of

314 lead may be associated with coal burning, brake and tire wear, vehicle exhaust emissions, and the

315 metal industry. We found several possible ways that human activities affect the lead in the

316 environment. However, further effort is needed to decrease and remove such pollution.

\section{Acknowledgments}

318 The authors acknowledge the constructive comments provided by both the reviewers and editors. 


\section{References}

320

321

322

323

324

325

326

327

328

329

330

331

332

333

334

335

336

337

338

339

340

341

342

343

344

345

346

347

348

349

350

351

352

353

354

355

356

357

358

359

360
Ayrault, S., Senhou, A., Moskura, M., Gaudry, A.: Atmospheric trace element concentrations in total suspended particles near Paris, France. Atmospheric Environment 44(30), 37003707 (2010)

Basha, S., Jhala, J., Thorat, R., Goel, S., Trivedi, R., Shah, K., Menon, G., Gaur, P., Mody, K.H., Jha, B.: Assessment of heavy metal content in suspended particulate matter of coastal industrial town, Mithapur, Gujarat, India. Atmospheric Research 97(1-2), 257-265 (2010)

$\mathrm{Bi}, \mathrm{X}$., Feng, Y., Wu, J., Wang, Y., Zhu, T.: Source apportionment of PM 10 in six cities of northern China. Atmospheric Environment 41(5), 903-912 (2007)

Bindler, R., Brännvall, M.L., Renberg, I., Emteryd, O., Grip, H.: Natural lead concentrations in pristine boreal forest soils and past pollution trends: A reference for critical load models. Environmental Science \& Technology 33(19), 3362-3367 (1999)

Bollhöfer, A., Rosman, K.J.R.: Isotopic source signatures for atmospheric lead: the Northern Hemisphere. Geochimica Et Cosmochimica Acta 65(11), 1727-1740 (2001)

Bove, M.A., Ayuso, R.A., Vivo, B.D., Lima, A., Albanese, S.: Geochemical and isotopic study of soils and waters from an Italian contaminated site: Agro Aversano (Campania). Journal of Geochemical Exploration 109(1-3), 38-50 (2011)

Charlson, R.J., Hofmann, D.J.: Climate forcing by anthropogenic aerosols. Science 255(5043), 423-430 (1992)

Chen, J., Tan, M., Li, Y., Zhang, Y., Lu, W., Tong, Y., Zhang, G., Li, Y.: A lead isotope record of shanghai atmospheric lead emissions in total suspended particles during the period of phasing out of leaded gasoline. Atmospheric Environment 39(7), 1245-1253 (2005)

Christian, T.J., Yokelson, R.J., Cárdenas, B., Molina, L.T., Engling, G., Hsu, S.C.: Trace gas and particle emissions from domestic and industrial biofuel use and garbage burning in central Mexico. Atmospheric Chemistry \& Physics Discussions 9(2), 565-584 (2009)

Cong, L., Zhang, H., Zhai, J., Yan, G., Wu, Y., Wang, Y., Ma, W., Zhang, Z., Chen, P.: The Blocking Effect of Atmospheric Particles by Forest and Wetland at Different Air Quality Grades in Beijing China. Environmental technology, 1-25 (2018). doi:10.1080/09593330.2018.1561759

Dai, Q.L.: Characterization and Source Identification of Heavy Metals in Ambient PM10 and PM2.5 in an Integrated Iron and Steel Industry Zone Compared with a Background Site. Aerosol \& Air Quality Research 15(3), 875-887 (2015)

Dang, D.H., Schäfer, J., Brachpapa, C., Lenoble, V., Durrieu, G., Dutruch, L., Chiffoleau, J.F., Gonzalez, J.L., Blanc, G., Mullot, J.U.: Evidencing the Impact of Coastal Contaminated Sediments on Mussels Through Pb Stable Isotopes Composition. Environmental Science \& Technology 49(19), 11438-11448 (2015)

Dawson, J.J.C., Tetzlaff, D., Carey, A.M., Raab, A., Soulsby, C., Killham, K., Meharg, A.A.: Characterizing $\mathrm{Pb}$ mobilization from upland soils to streams using $206 \mathrm{~Pb} / 207 \mathrm{~Pb}$ isotopic ratios. Environmental Science \& Technology 44(1), 243-249 (2010)

Degen, W.: 05/00862 Trace elements ( $\mathrm{Mn}, \mathrm{Cr}, \mathrm{Pb}, \mathrm{Se}, \mathrm{Zn}, \mathrm{Cd}$ and $\mathrm{Hg}$ ) in emissions from a pulverized coal boiler. Monatshefte Für Mathematik 67(3), 200-224 (1963)

Dickerson, R.R., Kondragunta, S., Stenchikov, G., Civerolo, K.L., Doddridge, B.G., Holben, B.N.: 
361

362

363

364

365

366

367

368

369

370

371

372

373

374

375

376

377

378

379

380

381

382

383

384

385

386

387

388

389

390

391

392

393

394

395

396

397

398

399

400

401

402

403

404

The impact of aerosols on solar ultraviolet radiation and photochemical smog. Science 278(5339), 827-830 (1997)

Dockery, D.W., Pope, C.A., Xu, X., ., Spengler, J.D., Ware, J.H., Fay, M.E., Ferris, B.G., Speizer, F.E.: An association between air pollution and mortality in six U.S. cities. New England Journal of Medicine 329(24), 1753 (1993)

Duan, J., Tan, J., Wang, S., Hao, J., Chai, F.: Size distributions and sources of elements in particulate matter at curbside, urban and rural sites in Beijing. Journal of Environmental Sciences 24(1), 87-94 (2012)

Duce, R.A., Hoffman, G.L., Zoller, W.H.: Atmospheric trace metals at remote northern and southern hemisphere sites: pollution or natural? Science 187(4171), 59-61 (1975)

Fang, G.C., Chang, C.N., Chu, C.C., Wu, Y.S., Fu, P.P., Yang, I.L., Chen, M.H.: Characterization of particulate, metallic elements of TSP, PM(2.5) and PM(2.5-10) aerosols at a farm sampling site in Taiwan, Taichung. Science of the Total Environment 308(1-3), 157-166 (2003)

Fang, G.C., Chang, C.Y.: Monitoring ambient air pollutants and apply Woods' model in the prediction seasonal dry deposition at Chang-Hua (urban) and Kao-Mei (wetland) county, Taiwan. Toxicology \& Industrial Health 30(8), 728 (2012)

Fang, G.C., Wu, Y.S., Huang, S.H., Rau, J.Y.: Dry deposition (downward, upward) concentration study of particulates and heavy metals during daytime, nighttime period at the traffic sampling site of Sha-Lu, Taiwan. Toxicology \& Industrial Health 18(8), 405 (2002)

Farao, C., Canepari, S., Perrino, C., Harrison, R.M.: Sources of PM in an Industrial Area : Comparison between Receptor Model Results and Semiempirical Calculations of Source Contributions. Aerosol \& Air Quality Research 14(6), 1558-1572(i (2014)

Florig, H.K.: China's air pollution risks. Environmental Science \& Technology 31(6), 274A-275A (1997)

Gallon, C., Tessier, A., Gobeil, C., Beaudin, L.: Sources and chronology of atmospheric lead deposition to a Canadian Shield lake: Inferences from Pb isotopes and PAH profiles. Geochimica Et Cosmochimica Acta 69(13), 3199-3210 (2005)

Gang, Jiuhai: Chemical composition and source apportionment of the ambient PM2.5 in Hangzhou, China. Particuology 18(1), 135-143 (2015)

Grousset, F.E., Quetel, C.R., Thomas, B., Buat-Menard, P., Donard, O.F., Bucher, A.: Transient pb isotopic signatures in the Western European atmosphere. Environmental Science \& Technology 28(9), 1605-1608 (1994)

Guor-ChengFang, Winn-JungHuang, Yuh-ShenWu, Chia-ChingLin, Yi-LiangHuang: Atmospheric Particulate and Metallic Elements at Five Characteristic Sampling Sites in Taiwan. Environmental Forensics 11(4), 293-299 (2010)

Han, L., Gao, B., Wei, X., Xu, D., Gao, L.: Spatial distribution, health risk assessment, and isotopic composition of lead contamination of street dusts in different functional areas of Beijing, China. Environmental Science and Pollution Research 23(4), 3247-3255 (2016). doi:10.1007/s11356-015-5535-y

Hao, Y., Guo, Z., Yang, Z., Fan, D., Fang, M., Li, X.: Tracking historical lead pollution in the coastal area adjacent to the Yangtze River Estuary using lead isotopic compositions. Environmental Pollution 156(3), 1325-1331 (2008)

Health, O.E.: Guidelines for air quality. Geneva World Health Organization (2000) 
405

406

407

408

409

410

411

412

413

414

415

416

417

418

419

420

421

422

423

424

425

426

427

428

429

430

431

432

433

434

435

436

437

438

439

440

441

442

443

444

445

446

447

448

Henderson, G.M.: New oceanic proxies for paleoclimate. Earth and Planetary Science Letters 203(1), 1-13 (2002). doi:https://doi.org/10.1016/S0012-821X(02)00809-9

Hieu, N.T., Lee, B.K.: Characteristics of particulate matter and metals in the ambient air from a residential area in the largest industrial city in Korea. Atmospheric Research 98(2-4), 526-537 (2010)

Huang, X., Zhao, F., Yu, G., Song, C., Geng, Z., Zhuang, P.: Removal of $\mathrm{Cu}, \mathrm{Zn}$, Pb, and $\mathrm{Cr}$ from Yangtze Estuary Using the Phragmites australis Artificial Floating Wetlands. BioMed Research International,2017,(2017-6-22) 2017(4), 6201048 (2017)

Huang, Y., Li, T., Wu, C., He, Z., Japenga, J., Deng, M., Yang, X.: An integrated approach to assess heavy metal source apportionment in peri-urban agricultural soils. Journal of Hazardous Materials 299, 540-549 (2015)

Jonsson, P., Bennet, C., Eliasson, I., Lindgren, E.S.: Suspended particulate matter and its relations to the urban climate in Dar es Salaam, Tanzania. Atmospheric Environment 38(25), 4175-4181 (2004)

Kaste, J.M., Friedland, A.J., Stürup, S.: Using Stable and Radioactive Isotopes To Trace Atmospherically Deposited Pb in Montane Forest Soils. Environmental Science \& Technology 37(16), 3560-3567 (2003)

Kelly, J., Thornton, I., Simpson, P.R.: Urban Geochemistry: A study of the influence of anthropogenic activity on the heavy metal content of soils in traditionally industrial and non-industrial areas of Britain. Applied Geochemistry 11(1-2), 363-370 (1996)

Ki, K.H., Lee, J.H., Jang, M.S.: Metals in airborne particulate matter from the first and second industrial complex area of Taejon city, Korea. Environmental Pollution 118(1), 41-51 (2002)

Kim, K.H.: Relationships between spatial and temporal variabilities in airborne metal distributions in Won Ju City, Korea. Environment International 29(7), 901-906 (2004)

Kim, K.H., Kim, D.S., Lee, T.J.: The temporal variabilities in the concentrations of airborne lead and its relationship to aerosol behavior. Atmospheric Environment 31(20), 3449-3458 (1997)

Kim, K.H., Lee, H.S., Youn, Y.H., Yun, S.T., Ro, C.U., Oh, J.M.: Studies of Spatial Variabilities of Airborne Metals Across Four Different Land-Use Types. Water Air \& Soil Pollution 138(14), 7-24 (2002)

Kyotani, T., Iwatsuki, M.: Characterization of soluble and insoluble components in PM2.5 and PM10 fractions of airborne particulate matter in Kofu city, Japan. Atmospheric Environment 36(4), 639-649 (2002). doi:https://doi.org/10.1016/S1352-2310(01)004940

Lee, C.S.L., Li, X.-D., Zhang, G., Li, J., Ding, A.-J., Wang, T.: Heavy metals and Pb isotopic composition of aerosols in urban and suburban areas of Hong Kong and Guangzhou, South China-Evidence of the long-range transport of air contaminants. Atmospheric Environment 41(2), 432-447 (2007). doi:https://doi.org/10.1016/j.atmosenv.2006.07.035

Li, R., Wiedinmyer, C., Hannigan, M.P.: Contrast and correlations between coarse and fine particulate matter in the United States. Science of the Total Environment s 456-457(7), 346-358 (2013)

Mai, T.N., Lee, B.K.: Size Distribution and Source Identification of Airborne Particulate Matter

PeerJ reviewing PDF | (2019:05:37675:2:0:NEW 5 Sep 2019) 
449

450

451

452

453

454

455

456

457

458

459

460

461

462

463

464

465

466

467

468

469

470

471

472

473

474

475

476

477

478

479

480

481

482

483

484

485

486

487

488

489

490

491 and Metallic Elements in a Typical Industrial City. Asian Journal of Atmospheric Environment 4(1), 9-19 (2010)

Marcazzan, G.M., Vaccaro, S., Valli, G., Vecchi, R.: Characterisation of PM10 and PM2.5 particulate matter in the ambient air of Milan (Italy). Atmospheric Environment 35(27), 4639-4650 (2001)

Mariepierre Pavageau, Christophe Pécheyran, †, E.M.K., Anne Morin, A., †, O.F.X.D.: Volatile Metal Species in Coal Combustion Flue Gas. Environmental Science \& Technology 36(7), 1561-1573 (2002)

Martinez-Haro, M., Taggart, M.A., Martín-Doimeadiøs, R.R., Green, A.J., Mateo, R.: Identifying sources of $\mathrm{Pb}$ exposure in waterbirds and effects on porphyrin metabolism using noninvasive fecal sampling. Environmental Science \& Technology 45(14), 6153-6159 (2011)

Mircea, M., Stefan, S., Fuzzi, S.: Precipitation scavenging coefficient: influence of measured aerosol and raindrop size distributions. Atmospheric Environment 34(29), 5169-5174 (2000). doi:https://doi.org/10.1016/S1352-2310(00)00199-0

Mishra, V.K., Kim, K.H., Hong, S., Lee, K.: Aerosol composition and its sources at the King Sejong Station, Antarctic peninsula. Atmospheric Environment 38(24), 4069-4084 (2004)

Morel, F.M.M.: The co - evolution of phytoplankton and trace element cycles in the oceans. Geobiology 6(3), 318 - 324 (2008)

Mukai, H., Atsushi Tanaka, A., Fujii, T., And, Y.Z., Hong, Y., Tang, J., Guo, S., Xue, H., Sun, Z., Jiti Zhou, A.: Regional Characteristics of Sulfur and Lead Isotope Ratios in the Atmosphere at Several Chinese Urban Sites. Environ.sci.technol 35(6), 1064 (2001)

Mukai, H., Furuta, N., Fujii, T., Ambe, Y., Sakamoto, K., Hashimoto, Y.: Characterization of sources of lead in the urban air of Asia using ratios of stable lead isotopes. Environ.sci.technol 27(7), 1347-1356 (1993)

Okuda, T., Katsuno, M., Naoi, D., Nakao, S., Tanaka, S., He, K., Ma, Y., Lei, Y., Jia, Y.: Trends in hazardous trace metal concentrations in aerosols collected in Beijing, China from 2001 to 2006. Chemosphere 72(6), 917-924 (2008)

Pan, Y., Tian, S., Li, X., Sun, Y., Li, Y., Wentworth, G.R., Wang, Y.: Trace elements in particulate matter from metropolitan regions of Northern China: Sources, concentrations and size distributions. Science of the Total Environment 537, 9 (2015)

Petaloti, C., Triantafyllou, A., Kouimtzis, T., Samara, C.: Trace elements in atmospheric particulate matter over a coal burning power production area of western Macedonia, Greece. Chemosphere 65(11), 2233-2243 (2006)

Polidori, A., Cheung, K.L., Arhami, M., Delfino, R.J.: Relationships between size-fractionated indoor and outdoor trace elements at four retirement communities in Southern California. Atmospheric Chemistry \& Physics Discussions 9(14), 4521-4536 (2009)

Quiterio, S.L., Loyola, J., Jr, A.P., Viviane, V., Arbilla, G.: Particulate matter and associated metal levels in a conservation area in the remaining tropical forest of Mata Atlântica, Brazil. Bulletin of Environmental Contamination \& Toxicology 77(5), 651 (2006)

Ragosta, M., Caggiano, R., D’Emilio, M., Macchiato, M.: Source origin and parameters influencing levels of heavy metals in TSP, in an industrial background area of Southern Italy. Atmospheric Environment 36(19), 3071-3087 (2002)

Peer) reviewing PDF | (2019:05:37675:2:0:NEW 5 Sep 2019) 
492

493

494

495

496

497

498

499

500

501

502

503

504

505

506

507

508

509

510

511

512

513

514

515

516

517

518

519

520

521

522

523

524

525

526

527

528

529

530

531

532

533

534

535

Salt, D.E., Blaylock, M., Kumar, N.P., Dushenkov, V., Ensley, B.D., Chet, I., Raskin, I.: Phytoremediation: a novel strategy for the removal of toxic metals from the environment using plants. Bio/technology 13(5), 468 (1995)

Seaton, A., ., Macnee, W., ., Donaldson, K., ., Godden, D., . Particulate air pollution and acute health effects. Lancet 345(8943), 176-178 (1995)

Shah, M.H., Shaheen, N.: Statistical analysis of atmospheric trace metals and particulate fractions in Islamabad, Pakistan. Journal of Hazardous Materials 147(3), 759-767 (2007)

Shah, M.H., Shaheen, N.: Annual and Seasonal Variations of Trace Metals in Atmospheric Suspended Particulate Matter in Islamabad, Pakistan. Water Air \& Soil Pollution 190(1-4), 13-25 (2008)

Shah, M.H., Shaheen, N., Jaffar, M.: Characterization, Source Identification and Apportionment of Selected Metals in TSP in an Urban Atmosphere. Environmental Monitoring \& Assessment 114(1-3), 573 (2006)

Shaheen, N., Shah, M.H., Jaffar, M.: A Study of Airborne Selected Metals and Particle Size Distribution in Relation to Climatic Variables and their Source Identification. Water Air \& Soil Pollution 164(1-4), 275-294 (2005)

Shi, G., Chen, Z., Xu, S., Zhang, J., Wang, L., Bi, C., Teng, J.: Potentially toxic metal contamination of urban soils and roadside dust in Shanghai, China. Environmental Pollution 156(2), 251 (2008)

Sun, W.P., Han, Z.B., Hu, C.Y., Pan, J.M.: Source composition and seasonal variation of particulate trace element fluxes in Prydz Bay, East Antarctica. Chemosphere 147, 318327 (2016)

Tan, M.G., Zhang, G.L., Li, X.L., Zhang, Y.X., Yue, W.S., Chen, J.M., Wang, Y.S., Li, A.G., Li, Y., Zhang, Y.M.: Comprehensive study of lead pollution in Shanghai by multiple techniques. Analytical Chemistry 78(23), 8044-8050 (2006)

Taylor, S.R., Mclennan, S.M.: The geochemical evolution of the continental crust. Review of Geophysics 33(2), 241-265 (1995)

Uzu, G., Sobanska, S., Sarret, G., Muñoz, M., Dumat, C.: Foliar Lead Uptake by Lettuce Exposed to Atmospheric Fallouts. In: 2010, pp. 504-505

Vallius, M., Janssen, N.A., Heinrich, J., Hoek, G., Ruuskanen, J., Cyrys, J., Van, G.R., de Hartog, J.J., Kreyling, W.G., Pekkanen, J.: Sources and elemental composition of ambient PM(2.5) in three European cities. Science of the Total Environment 337(1-3), 147-162 (2005)

Veysseyre, A.M., Bollhöfer, A.F., Rosman, K.J., Ferrari, C.P., Boutron, C.F.: Tracing the origin of pollution in French Alpine snow and aerosols using lead isotopic ratios. Environmental Science \& Technology 35(22), 4463 (2001)

Wang, C., Wang, J., Yang, Z., Mao, C., Ji, J.: Characteristics of lead geochemistry and the mobility of $\mathrm{Pb}$ isotopes in the system of pedogenic rock-pedosphere-irrigated riverwatercereal-atmosphere from the Yangtze River delta region, China. Chemosphere 93(9), 1927-1935 (2013)

Wang, H., Zhuang, Y., Wang, Y., Sun, Y., Yuan, H., Zhuang, G., Hao, Z.: Long-term monitoring and source apportionment of PM2.5/PM10 in Beijing, China. Journal of Environmental Sciences 20(11), 1323-1327 (2008)

Wang, J., Pan, Y., Tian, S., Chen, X., Wang, L., Wang, Y.: Size distributions and health risks of particulate trace elements in rural areas in northeastern China. Atmospheric Research

Peer] reviewing PDF | (2019:05:37675:2:0:NEW 5 Sep 2019) 
536

537

538

539

540

541

542

543

544

545

546

547

548

549

550

551

552

553

554

555

556

557

558

559

168(3), 191-204 (2016)

Wei, F., Yang, Z., Jiang, D., Liu, Z., Sun, B.: Basic statistics and characteristics of background values of soil elements in China. China environmental monitoring(1), 1-6 (1991)

Wiederhold, J.G.: Metal Stable Isotope Signatures as Tracers in Environmental Geochemistry. Environmental Science \& Technology 49(5), 2606-2624 (2015)

Xu, L., Yu, Y., Yu, J., Chen, J., Niu, Z., Yin, L., Zhang, F., Liao, X., Chen, Y.: Spatial distribution and sources identification of elements in PM2.5 among the coastal city group in the Western Taiwan Strait region, China. Science of the Total Environment 442(1), 77-85 (2013)

Yang, Y., Wang, Y., Huang, W., Hu, B., Wen, T., Zhao, Y.n.: Size Distributions and Elemental Compositions of Particulate Matter on Clears Hazy and Foggy days in Beijing, China. Advances in Atmospheric Sciences 27(3), 663-675 (2010)

Yongming, H., Peixuan, D., Junji, C., Posmentier, E.S.: Multivariate Analysis of Heavy Metal Contamination in Urban Dusts of Xi'an, Central China. Science of the Total Environment 355(1-3), 176-186 (2006)

Zajusz-Zubek, E., Konieczyński, J.: Dynamics of trace elements release in a coal pyrolysis process 㶦. Fuel 82(10), 1281-1290 (2003)

Zhang, G.L., Yang, F.G., Zhao, W.J., Zhao, Y.G., Yang, J.L., Gong, Z.T.: Historical change of soil Pb content and $\mathrm{Pb}$ isotope signatures of the cultural layers in urban Nanjing. Catena 69(1), 51-56 (2007)

Zheng, J., Tan, M.G., Shibata, Y., Tanaka, A., Li, Y., Zhang, G.L., Zhang, Y.M., Shan, Z.: Characteristics of lead isotope ratios and elemental concentrations in PM10 fraction of airborne particulate matter in Shanghai after the phase-out of leaded gasoline. Atmospheric Environment 38(8), 1191-1200 (2004). doi:10.1016/j.atmosenv.2003.11.004 
Figure 1

Position of the sampling site

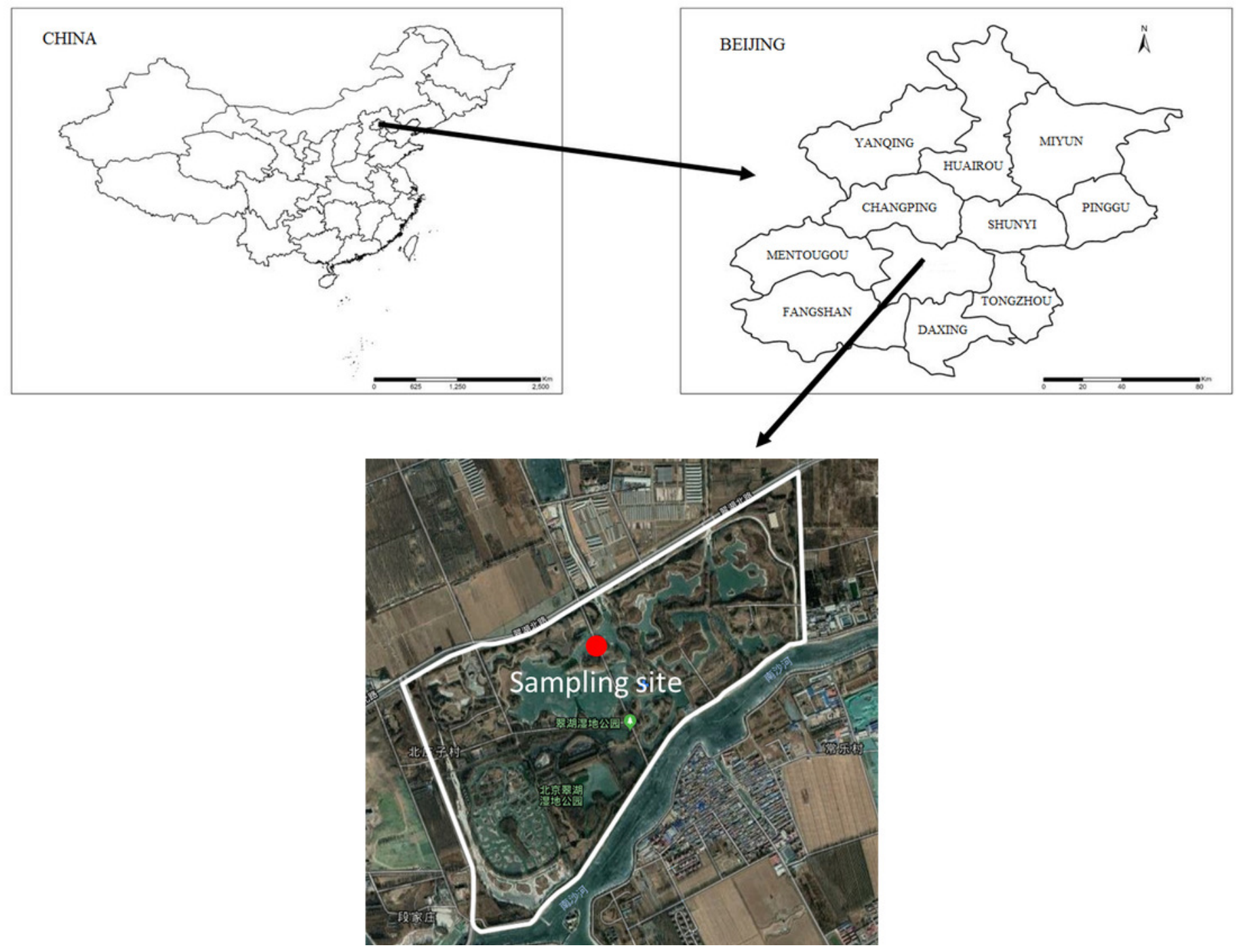


Figure 2

Seasonal variations in TSP $\left( \pm\right.$ SE) expressed in $\mathrm{ng} / \mathrm{m}^{3}$ during the study period

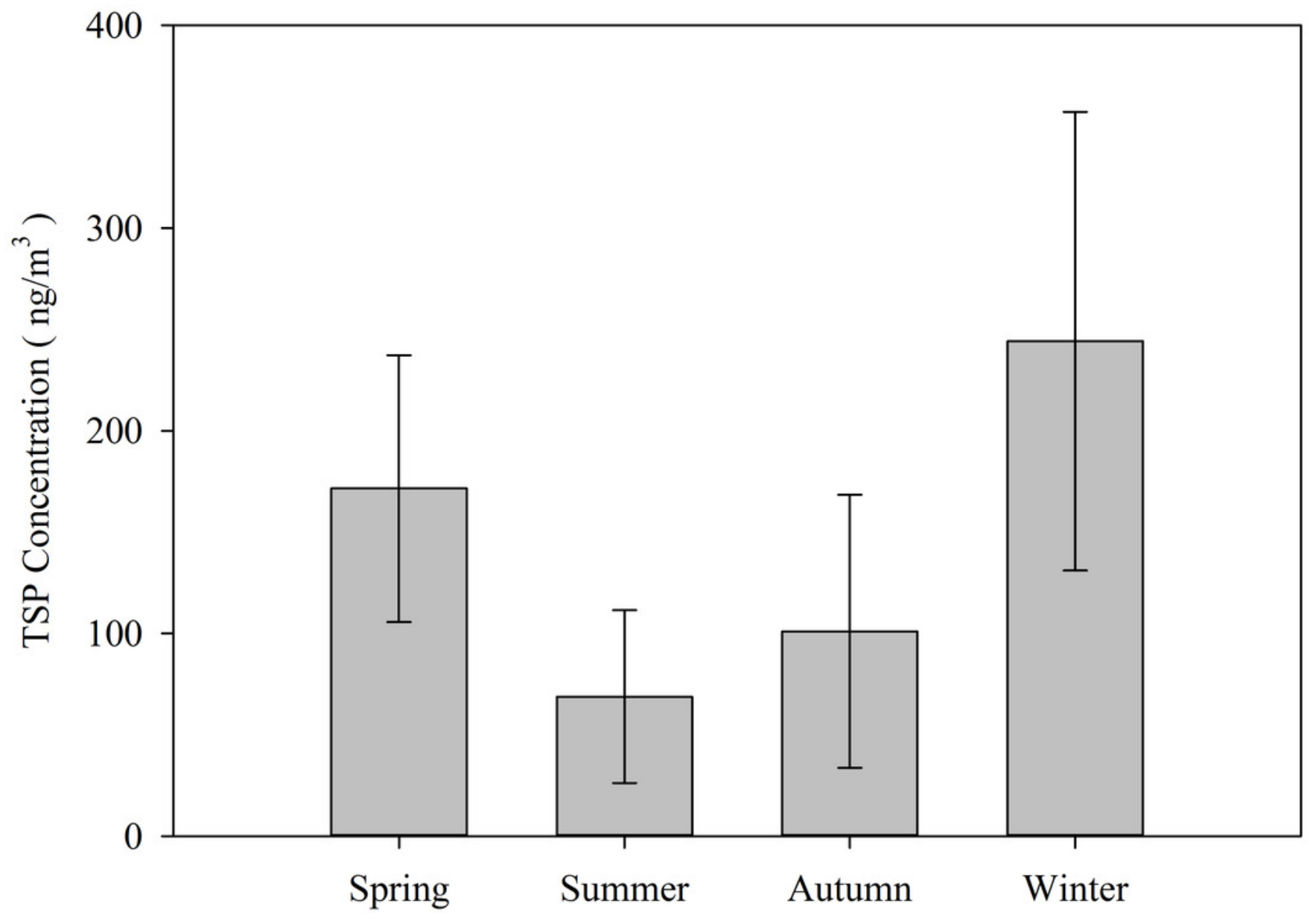


Figure 3

Seasonal variations in the lead concentrations $\left( \pm S E\right.$ ) expressed in $\mathrm{ng} / \mathrm{m}^{3}$ during the study period

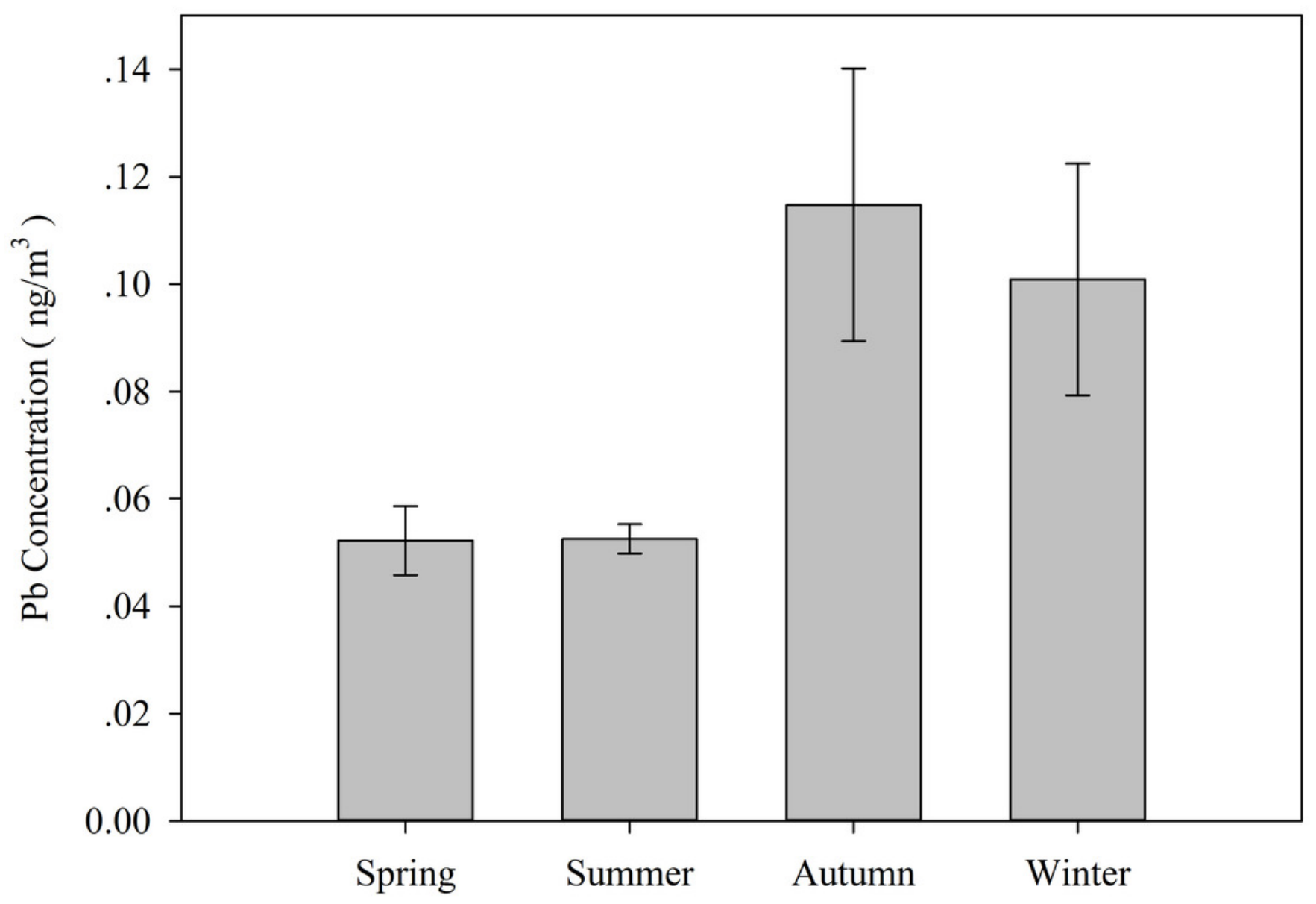


Figure 4

Lead enrichment factors during the study period

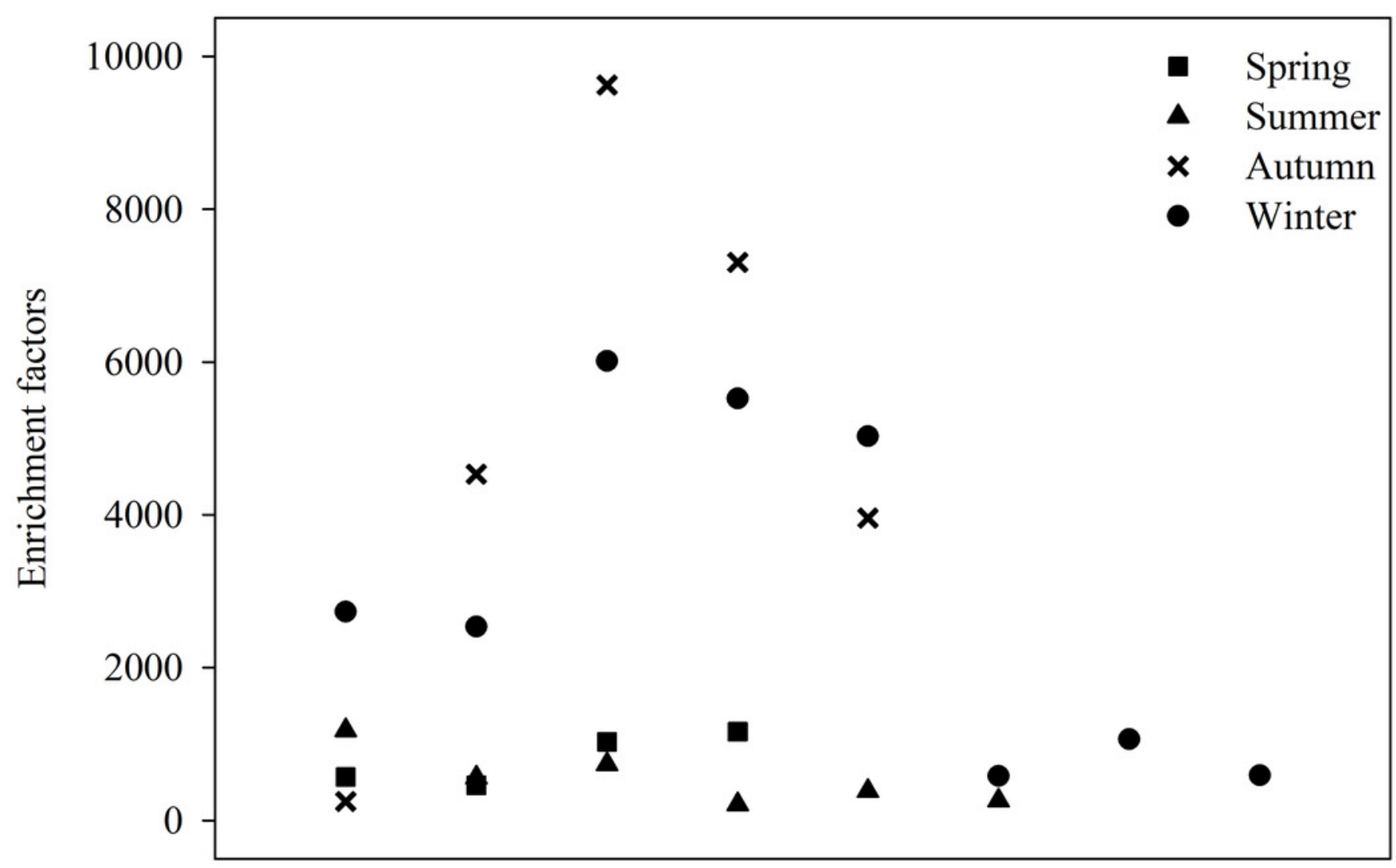


Table $\mathbf{1}$ (on next page)

Lead isotope compositions 


\begin{tabular}{cccccc}
\hline & & Spring & Summer & Autumn & Winter \\
\hline${ }^{208} \mathrm{~Pb} / 204 \mathrm{~Pb}$ & Mean & 36.773 & 37.033 & 36.795 & 36.596 \\
& Range & $36.710-36.888$ & $36.471-37.949$ & $36.145-37.559$ & $36.233-37.166$ \\
& Mean & 2.184 & 2.162 & 2.171 & 2.189 \\
${ }^{208} \mathrm{~Pb} / 206 \mathrm{~Pb}$ & Range & $2.165-2.204$ & $2.094-2.197$ & $2.112-2.206$ & $2.160-2.202$ \\
& Mean & 15.568 & 15.600 & 15.529 & 15.517 \\
${ }^{207} \mathrm{~Pb} / 204 \mathrm{~Pb}$ & Range & $15.443-15.688$ & $15.429-15.761$ & $15.129-15.732$ & $15.350-15.773$ \\
& Mean & 16.838 & 17.134 & 16.957 & 16.720 \\
${ }^{206} \mathrm{~Pb} / 204 \mathrm{~Pb}$ & Range & $16.678-16.971$ & $16.758-18.121$ & $16.490-17.787$ & $16.505-17.034$ \\
& Mean & 1.082 & 1.098 & 1.092 & 1.078 \\
& Range & $1.063-1.098$ & $1.069-1.168$ & $1.061-1.132$ & $1.069-1.100$ \\
\hline${ }^{206} \mathrm{~Pb} / 207 \mathrm{~Pb}$ & & &
\end{tabular}




\section{Table 2 (on next page)}

Lead concentrations in TSP in the Cuihu Wetland and other sites worldwide 


\begin{tabular}{|c|c|c|c|c|c|}
\hline City & Size & $\mathrm{Pb}\left(\mathrm{ng} / \mathrm{m}^{3}\right)$ & Season & Character & Reference \\
\hline Shenyang, China & TSP & 0.115 & $2013-2014$ & Farmland & (Wang et al. 2016) \\
\hline Hailun, China & TSP & 0.037 & 2013-2014 & Farmland & (Wang et al. 2016) \\
\hline Taichung, Taiwan & TSP & 0.574 & 2002 & Farmland & (Fang et al. 2003) \\
\hline Tongyu, China & TSP & 0.031 & 2013-2014 & Grassland & (Wang et al. 2016) \\
\hline $\begin{array}{c}\text { Haeng Goo Dong, } \\
\text { Korea }\end{array}$ & TSP & 0.084 & 1991-1995 & Grassland & (Kim 2004) \\
\hline Taejon, Korea & TSP & 0.260 & 2002 & Industrial & (Ki et al. 2002) \\
\hline Islamabad & TSP & 0.214 & 2003 & Industrial & (Shaheen et al. 2005) \\
\hline Islamabad & TSP & 0.128 & 2004 & Industrial & (Shah,Shaheen 2007) \\
\hline Quan-xing, Taiwan & TSP & 0.015 & 2010 & Industrial & $\begin{array}{c}\text { (Guor-ChengFang et } \\
\text { al. 2010) }\end{array}$ \\
\hline Chang-hua, Taiwan & TSP & 0.019 & 2010 & Downtown & $\begin{array}{c}\text { (Guor-ChengFang et } \\
\text { al. 2010) }\end{array}$ \\
\hline Taiwan & TSP & 0.180 & 2004 & Downtown & (Fang et al. 2002) \\
\hline Beijing, China & TSP & 0.690 & 2005 & Residential & (Okuda et al. 2008) \\
\hline He-mei, Taiwan & TSP & 0.016 & 2010 & Residential & $\begin{array}{c}\text { (Guor-ChengFang et } \\
\text { al. 2010) }\end{array}$ \\
\hline Islamabad, Pakistan & TSP & 0.144 & 2004-2005 & Urban area & (Wang et al. 2016) \\
\hline Chang-Hua, Taiwan & TSP & 0.034 & 2009-2010 & Urban area & (Fang,Chang 2012) \\
\hline $\begin{array}{c}\text { Changbai Mountain, } \\
\text { China }\end{array}$ & TSP & 0.018 & 2013-2014 & Forest & (Wang et al. 2016) \\
\hline Ilha Grande, Brazil & TSP & 0.001 & 2005 & Forest & (Quiterio et al. 2006) \\
\hline Bei-shi, Taiwan & TSP & 0.044 & 2010 & Suburban/Coastal & $\begin{array}{c}\text { (Guor-ChengFang et } \\
\text { al. 2010) }\end{array}$ \\
\hline Gao-Mei, Taiwan & TSP & 0.025 & 2009-2010 & Wetland & (Fang,Chang 2012) \\
\hline Gao-mei, Taiwan & TSP & 0.010 & 2010 & Wetland & $\begin{array}{c}\text { (Guor-ChengFang et } \\
\text { al. 2010) }\end{array}$ \\
\hline Beijing, China & TSP & 0.080 & $2016-2017$ & Wetland & This study \\
\hline
\end{tabular}




\section{Table 3 (on next page)}

Isotope ratios and the elemental content of possible additional lead sources 


\begin{tabular}{|c|c|c|c|}
\hline Materials & ${ }^{206} \mathrm{~Pb} /{ }^{207} \mathrm{~Pb}$ & ${ }^{208} \mathrm{~Pb} / 206 \mathrm{~Pb}$ & Reference \\
\hline Leaded vehicle exhaust & 1.11 & 2.194 & (Mukai et al. 1993) \\
\hline Unleaded automobile exhaust & $1.131-1.164$ & $2.106-2.142$ & (Tan et al. 2006) \\
\hline Coal & $1.153-1.182$ & $2.090-2.220$ & (Mukai et al. 2001) \\
\hline Metallurgic dust & $1.161-1.185$ & $2.054-2.100$ & (Tan et al. 2006) \\
\hline Industrial sources & 1.176 & 2.1 & (Mukai et al. 2001) \\
\hline TSP (Spring) & $1.063-1.098$ & $2.165-2.204$ & This study \\
\hline TSP (Summer) & $1.069-1.168$ & $2.094-2.197$ & This study \\
\hline TSP (Autumn) & $1.061-1.132$ & $2.112-2.206$ & This study \\
\hline TSP (Winter) & $1.069-1.200$ & $2.160-2.202$ & This study \\
\hline
\end{tabular}

1 